\title{
Response to Selection for Increased Individual Grain Mass in Pearl Millet
}

\author{
F. R. Bidinger* and D. S. Raju
}

\begin{abstract}
Although pearl millet [Pennisetum glaucum (L.) R. Br.] is traditionally a small grain crop, a trait associated with adaption to marginal environments, there are both agronomic and usage-related reasons for seeking to increase individual grain mass (or size). Individual grain mass appears to have a low to moderate heritability in pearl millet, suggesting that genetic improvement based on some form of progeny testing is likely to be effective. The objective of this research was to quantify the percentage increase in individual grain mass that could be achieved in a modern open-pollinated millet cultivar, ICMS 7703, by two cycles of recurrent $S_{1}$ progeny selection for increased grain mass and maintenance of grain yield potential. Evaluated across 10 test environments, two cycles of selection achieved an $18 \%$ increase in individual grain mass (8.05-9.52 mg per grain), with no change in grain yield per square meter. Substantial improvement in individual grain mass in pearl millet is thus possible with targeted recurrent selection, where larger seed size provides an agronomic or processing advantage, or enhances consumer preference.
\end{abstract}

$\mathrm{I}$ NDIVIDUAL GRAIN MASS in pearl millet varies from less than $5 \mathrm{mg}$ per grain to more than $15 \mathrm{mg}$ (Murthy et al., 1967). Small individual grain mass-and its correlate of a large grain number-is an important adaptive feature of pearl millet to the arid climates in which it evolved, allowing short grain filling periods, rapid seed germination, and large seed numbers to compensate for high rates of failure in seedling establishment (DeWet et al., 1992). Large individual grain mass, in contrast, is a useful characteristic in managed agricultural environments. Large grain mass is advantageous in crop establishment, conferring improved rates of seedling emergence and plant stands (Lawan et al., 1985), faster initial seedling growth (Siband et al., 1979), and faster early crop growth (Chhina and Phul, 1982). In addition, large grain size (mass) improves processing quality of the grain, increasing the ease of decortication and improving flour yield with both commercial milling and handpounding milling methods (Rooney and McDonough, 1987). A large grain size can bring a higher market price (Phul and Athwal, 1969) and is often cited as a preferred characteristic in new pearl millet cultivars in farmer surveys (M.L. Whitaker, 1996, personal communication). Thus, there are a number of potential reasons for including the improvement of individual grain mass among the breeding objectives for the crop.

Estimates of the heritability of individual grain mass in pearl millet vary widely, depending on materials and experimental designs used. Virk (1988) summarized published estimates of narrow-sense heritability: less

International Crops Research Institute for the Semi-Arid Tropics, ICRISAT Patancheru PO, Andhra Pradesh 502 324, India. ICRISAT Journal Article No. 1962 Received 4 Nov. 1998. *Corresponding author (f.bidinger@cgiar.org).

Published in Crop Sci. 40:68-71 (2000). than $30 \%$ from four diallel studies, 50 to $70 \%$ from studies using various selfing procedures and 30 to $50 \%$ on the basis of various mating design procedures. Hash (1986) concluded from a review of the literature that the heritability of seed size is likely to be low because of effects on grain mass of seed number or percentage seed set, inbreeding depression, and inter- and intraplant and panicle competition for assimilates. He concluded that for selection for seed size to be successful, the breeder must limit the effects of non-heritable sources of variation. Despite attempts to control such sources of variability in a parent-progeny regression study, Hash (1986) estimated narrow-sense heritability for grain mass in pearl millet to be only $20 \%$.

The majority of studies of the genetics of grain mass also indicate that the non-additive components of variance (or specific combining ability) are as, or more, important than the additive component (or general combing ability). Virk (1988) reported that for 18 published diallel cross studies, the variance attributable to specific combining ability effects was on average seven times greater than that attributed to general combining ability, but for 15 line $\times$ tester studies, the contributions of the two components were similar. Because of relatively low narrow-sense heritability estimates in their own studies, and the predominance of non-additive genetic variation, both Phul and Athwal (1969) and Hash (1986) recommended that a selection procedure based on some form of progeny testing would be the most effective means of improving grain mass. This study was carried out to quantify the improvement in individual grain mass, following two cycles of modified phenotypic/ S1 progeny selection for grain mass in an adapted, high yielding, open-pollinated pearl millet variety.

\section{MATERIALS AND METHODS}

\section{Selection for Grain Mass}

We carried out two cycles of a modified S1 progeny selection for individual grain mass in the open-pollinated variety ICMS 7703, a synthetic with a small to intermediate grain size, formed by intermating seven inbred lines resistant to the downy mildew fungus [Sclerospora graminicola (Sacc.) J. Schrot.], originating from crosses of Indian $\times$ West African breeding lines (Jain et al. 1991). Our selection method involved a first stage phenotypic selection for 100 grain mass, followed by replicated testing of S1 progeny of the selected plants to confirm, on a genotypic basis, the worth of the phenotypic selections made in the S0 generation. This procedure was intended to eliminate progenies with a large individual grain mass resulting from various non-heritable causes cited by Hash (1968).

During the 1981 rainy season (Cycle 1) at ICRISAT Center,

Abbreviations: C, cycle of selection; S1, first selfed generation; syn 0 , first recombination generation; syn 1 , second recombination generation. 
Patancheru, India, we grew approximately 1500 individual spaced $(0.75$ by $0.75 \mathrm{~m})$ plants from a breeders seed lot of the variety, hereafter referred to as Cycle 0 (C0) of ICMS 7703. Plants were sown in a solid block on the upwind edge of a field with no millet upwind within $500 \mathrm{~m}$ to limit effects of pollen from sources other than the population. We allowed the main panicle to pollinate naturally, but self-pollinated (by bagging) one tiller panicle. We harvested and threshed all the open-pollinated main shoot panicles, did triplicate 100-grain counts on the threshed grain, and weighed the counted samples to determine 100-grain mass. We harvested all of the selfed tiller panicles but only threshed and retained the selfed seed of the 120 individual plants with the largest main panicle 100grain mass. These 120 progenies were evaluated for 100 -grain mass and grain yield per square meter in a field trial in the 1982 rainy season at ICRISAT Center. A subset of 64 progenies, which had the largest 100-grain mass in 1982, were retested in the 1984 rainy season (the 1983 evaluation failed). Individual plots of both trials were 1 row of $4.0 \mathrm{~m}$ by $0.75 \mathrm{~m}$, replicated three times in an randomized complete block (RCB) design. Data on days to flowering, grain yield, and 100 -grain mass were recorded on all plots.

We selected $25 \mathrm{~S} 1$ progenies for recombination to form the Cycle 1 (C1) of ICMS 7703 on the basis of the results of the 1984 trial. Selection was based on three criteria: large grain mass, time to flowering within 1 standard deviation (SD) of the mean of the 64 entry S1 progeny set (to retain the original cultivar maturity), and grain yield per square meter greater or equal to the mean of the 64 entry S1 progeny set (to retain the original yield level of the cultivar). The selected progeny were planted as individual rows and random-mated by handpollination, (applying bulk pollen from all progeny to a similar number of panicles of each individual row) during the 19841985 dry season. An equal quantity of seed from the pollinated panicles of each progeny was bulked to form the first recombination generation (Syn 0 ) of the $\mathrm{C} 1$ cycle bulk of the variety.

We initiated a second cycle of selection during the 1987 rainy season on the $\mathrm{C} 1$ bulk of ICMS 7703, following the same modified S1 procedure as in the first cycle. We evaluated grain mass in approximately 1000 open-pollinated main panicles and selected 96 plants with large grain mass for evaluation in an RCB design in the 1988 rainy season at ICRISAT Centre, again using the selfed seed from the first tiller. We selected $25 \mathrm{~S}$ progenies for recombination on the basis of large grain mass, time to flowering within 1 SD of the mean, and grain yield per square meter equal to or greater than the mean of the 96 entry S1 progeny set. Selected progenies were recombined by hand pollination, in the same manner as the $\mathrm{C} 1$, during the 1988-1989 dry season, to form the Cycle 2 (C2) bulk. At the same time, we produced fresh seed stocks of the $\mathrm{C} 0$ and $\mathrm{C} 1$ bulks by hand pollinating approximately 100 panicles of each bulk with mixed pollen from at least as many additional panicles from the same bulk to have seed for all cycles from the same seed production environment. This meant, however, that the $\mathrm{C} 0$ and $\mathrm{C} 1$ cycle bulks were Syn 1 bulks (second recombination generation) and the $\mathrm{C} 2$ bulk was Syn 0 bulk.

\section{Evaluation of Reselected Cycles of ICMS $\mathbf{7 7 0 3}$}

We compared the original $\mathrm{C} 0$ and the selected $\mathrm{C} 1$ cycles on the ICRISAT-Patancheru farm in yield trials during the rainy seasons of 1985 and 1986 . The yield trial plots were 4 row by $4.0-\mathrm{m}$ by $0.75-\mathrm{m}$ plots with 8 replications, in an RCB design. The trials were grown on alfisol (Udic Rhodustalf) fields under non-limiting fertility conditions. Data (oven dry weight) on grain yields per square meter were recorded on
$3.0 \mathrm{~m}$ of the center two rows $\left(4.5 \mathrm{~m}^{2}\right)$. Individual grain mass was determined from the dry mass of triplicate 100-grain samples for each plot, and grain number per unit area was calculated by dividing threshed grain yield per square meter by individual grain mass for each plot.

We compared the $\mathrm{C} 0, \mathrm{C} 1$, and $\mathrm{C} 2$ cycles of ICMS 7703 in 10 different trials from 1989 to 1991 . Six of the 10 trials were conducted at ICRISAT-Patancheru farm, during the rainy seasons of each of the $3 \mathrm{yr}$, on two alfisol (Udic Rhodustalf) fields differing in input level. One field was high input (80-100 $\mathrm{kg} \mathrm{N}$ and 19 to $25 \mathrm{~kg} \mathrm{P}$ ha $^{-1}$ test field with supplemental irrigation as needed, the other a low input, $(20 \mathrm{~kg} \mathrm{~N}$ and $9 \mathrm{~kg}$ $\mathrm{P} \mathrm{ha}^{-1}$ ), completely rainfed test field. Two of the 10 trials were conducted on a silty alluvial soil the Government Livestock Farm at Hisar, Haryana state, in north India, during the rainy seasons of 1990 and 1991 . Both trials were managed as high input trials with several supplemental irrigations. The final two trials were conduced on a alfisol (Udic Rhodustalf) under high input conditions at ICRISAT-Patancheru during the dry season (January-May) of 1991; one was a control environment that was irrigated regularly throughout the season; the other a stress environment that was subjected to severe moisture stress during flowering and grain filling by terminating irrigation just before panicle emergence.

Plot size in all trials, except the 1991 dry season trials, was 4 rows by $4.0 \mathrm{~m}$ by $0.75 \mathrm{~m}$, replicated 8 to 10 times. Plot size in the dry season trials was 4 rows by $4.0 \mathrm{~m}$ by $0.60 \mathrm{~m}$. Data (oven dry weight) on yield and yield components were recorded on $3.0 \mathrm{~m}$ of the center two rows $\left(4.5\right.$ or $\left.3.6 \mathrm{~m}^{2}\right)$. Individual grain mass was determined from the dry mass of triplicate 100 -grain samples for each plot, and grain number per unit area was calculated by dividing threshed grain yield per square meter by individual grain mass.

Data from the 1985 and 1986 comparisons of the C0 and C1 cycles were analyzed by SAS PROC ANOVA (SAS 1985), as a multi-environment trial with years as environments. Data from the 1989 to 1991 trials were analyzed by SAS PROC GLM (SAS 1985) as a multi-environment trial with location $X$ year combinations as environments. In both analyses, environments were considered as random effects and cycle bulks as fixed effects. The two degrees of freedom for cycle in the 1989 to 1991 analyses were partitioned into orthogonal single degree of freedom comparisons of $\mathrm{C} 0$ with the mean of both selected cycles ( $\mathrm{C} 0$ vs. $\mathrm{C} 1 / \mathrm{C} 2)$, and $\mathrm{C} 1$ vs. $\mathrm{C} 2$. There were no environment $\times$ cycle interactions in either analyses, so only cycle means are presented.

\section{RESULTS AND DISCUSSION Response to Selection}

The first cycle of S1 progeny selection for grain mass significantly increased individual grain mass by $16.3 \%$ (from $7.89 \mathrm{mg}$ per grain in $\mathrm{C} 0$ to $9.18 \mathrm{mg}$ per grain in C1) in the 1985 and 1986 evaluations (Tables 1 and 2). In the more extensive evaluations in 1989 to 1991 , selection resulted in a progressive and significant increase in grain size from $8.05 \mathrm{mg}$ per grain $(\mathrm{C} 0)$ to 8.61 $\mathrm{mg}$ per grain $(\mathrm{C} 1)$ to $9.55(\mathrm{C} 2) \mathrm{mg}$ per grain over the three cycles. This represented a $7.0 \%$ increase from $\mathrm{C} 0$ to $\mathrm{C} 1$, a $10.9 \%$ increase from $\mathrm{C} 1$ to $\mathrm{C} 2$ and a cumulative $18.6 \%$ increase from $\mathrm{C} 0$ to $\mathrm{C} 2$ (Tables 1 and 2). The mean individual grain mass in the two selected cycles $(\mathrm{C} 1 / \mathrm{C} 2)$ was significantly greater than that of the $\mathrm{C}$, and that of the $\mathrm{C} 2$ was significantly greater than that of the $\mathrm{C} 1$ cycle (single degree of freedom comparisons 
Table 1. Analyses of variance for individual grain mass (mg), grain yield $\left(\mathrm{g} \mathrm{m}^{-2}\right)$, and grain number (no. $\left.\mathbf{m}^{-2}\right)$ after two cycles of $\mathbf{S 1}$ selection for increased grain mass in pearl millet synthetic variety ICMS 7703. The evaluations are for the original (C0) and the first (C1) cycles of selection in 1985 and 1986, and the C0, C1 and second (C2) cycles of selection from 1989 to 1991.

\begin{tabular}{|c|c|c|c|c|}
\hline \multirow[b]{2}{*}{ Source of variation } & \multirow[b]{2}{*}{ df } & \multicolumn{3}{|c|}{ Mean squares } \\
\hline & & Grain mass & Grain yield $\dagger$ & Grain no. \\
\hline \multicolumn{5}{|l|}{1985 and 1986 evaluations: } \\
\hline Environment & 1 & 0.0536 & 2.041 & 209.35 \\
\hline Rep (environment) & 14 & 0.0056 & 7.431 & 76.01 \\
\hline Cycle of selection & 1 & $\mathbf{0 . 1 3 3 9} * * *$ & 0.018 & 261.38*** \\
\hline Environment $\times$ cycle & 1 & 0.0001 & 0.901 & 2.23 \\
\hline Error & 14 & 0.0048 & 1.623 & 13.12 \\
\hline $\mathrm{CV}$ & & $8.1 \%$ & $12.2 \%$ & $12.3 \%$ \\
\hline \multicolumn{5}{|l|}{1989 to 1991 evaluations: } \\
\hline Environment & 9 & 0.4962 & 171.271 & 1637.46 \\
\hline Rep (environment) & 91 & 0.0090 & 3.103 & 36.01 \\
\hline Cycle of selection & 2 & $0.5672 * * *$ & 0.344 & $\mathbf{5 3 5 . 6 0} * * *$ \\
\hline $\mathrm{CO}$ v. C1/C2 & 1 & $0.7142 * * *$ & - & $660.11 * * *$ \\
\hline C1 v. C2 & 1 & $0.4436 * * *$ & - & 464.61*** \\
\hline Environment $\times$ cycle & 18 & 0.0088 & 1.504 & 24.18 \\
\hline Error & 178 & 0.0059 & 1.256 & 21.26 \\
\hline CV & & $8.6 \%$ & $14.5 \%$ & $16.5 \%$ \\
\hline
\end{tabular}

$* * * \boldsymbol{P}<\mathbf{0 . 0 0 1}$.

$\dagger$ Values for grain yield are $10^{-3} \times$ actual mean squares.

+ Values for grain number are $10^{-6} \times$ actual mean squares.

in Table 1). The differences in grain size among cycles were significant in nine of the 10 individual trials, including the grain filling stress trial in 1991, when mean grain sizes were reduced by approximately $40 \%$ (data not presented).

The response to selection for increased grain mass in this experiment- $18.6 \%$ over two cycles of selectioncompares favorably with the increases reported by Khadr and Oyinloye (1978, quoted by Hash, 1986) and Hash (1986). The first authors reported an increase of $18 \%$ in individual grain mass in one test location (but no increase in the other) following four cycles of mass selection in a broad based composite. Hash (1986), working with a very narrow-based population, in which one of the parents had an individual grain mass of more than $20 \mathrm{mg}$, reported an increase of $28 \%$ in one cycle of full sib progeny selection. A second cycle of selection had no further effect on grain mass, however. Both of these studies used only two evaluation environments, however, so that the increases in grain mass in this experiment, on the basis of 10 evaluation environments, provide a better estimate of likely response to selection.

The increase in individual grain mass as a result of selection had no effect on grain yield per square meter in either the first or second cycle of selection (Table 1).

Table 2. Cycle means for individual grain mass, grain yield $\mathbf{m}^{-2}$, and grain number $\mathrm{m}^{-2}$ for the original (CO), first (C1), and second (C2) cycles of $\mathrm{S} 1$ recurrent selection for increased grain mass in pearl millet synthetic variety ICMS 7703. Means are based on two test environments in 1985 and 1986, and on 10 test environments from 1989 to 1991.

\begin{tabular}{|c|c|c|c|}
\hline Cycle of selection & Grain mass & Grain yield & Grain no. \\
\hline & mg & $\mathbf{g ~ m}^{-2}$ & $1000 \mathrm{~m}^{-2}$ \\
\hline \multicolumn{4}{|c|}{1985 and 1986 evaluations: } \\
\hline Co & 7.89 & 330 & 41.9 \\
\hline C1 & 9.18 & 332 & 36.1 \\
\hline LSD $(P<0.05)$ & 0.52 & 31 & 3.6 \\
\hline \multicolumn{4}{|c|}{1989 to 1991 evaluations: } \\
\hline Co & 8.05 & 243 & 30.1 \\
\hline C1 & 8.61 & 247 & 28.6 \\
\hline C2 & 9.55 & 244 & 25.4 \\
\hline LSD $(P<0.05)$ & 0.20 & 9 & 1.2 \\
\hline
\end{tabular}

The overall mean yields of the $\mathrm{C} 0$ and $\mathrm{C} 1$ cycles of ICMS 7703 in the 1985 and 1986 evaluations were virtually identical, 330 and $332 \mathrm{~g} \mathrm{~m}^{-2}$ (Table 2). Similarly, there were no differences in grain yield among the three generations in the 10-test environments in 1989 to 1991 (Table 1). Mean grain yields were $243 \mathrm{~g} \mathrm{~m}^{-2}$ (C0), 247 $\mathrm{g} \mathrm{m}^{-2}$ (C1), and 244 (C2) $\mathrm{g} \mathrm{m}^{-2}$ (Table 2). In both sets of comparisons, the increased individual grain mass was accompanied by a significant decrease in grain numbers per unit area of similar magnitude. In the 1985 and 1986 evaluations, grain numbers declined by $13.8 \%$ between the $\mathrm{C} 0$ and $\mathrm{C} 1$ generations (Tables 1 and 2). In the more extensive 1989 to 1991 evaluations, grain numbers declined by $5.0 \%$ between $\mathrm{C} 0$ and $\mathrm{C} 1$ and $11.0 \%$ between $\mathrm{C} 1$ and $\mathrm{C} 2$, for a cumulative decrease of $15.6 \%$ between $\mathrm{C} 0$ and $\mathrm{C} 2$. The differences between both the $\mathrm{C} 0$ and $\mathrm{C} 1 / \mathrm{C} 2$ cycles and the $\mathrm{C} 1$ and $\mathrm{C} 2$ cycles were significant (Table 1). The decreases in grain numbers were due entirely to decreases in grain numbers per panicle, since there were no effects of selection for individual grain mass on productive panicle numbers (data not presented).

A tradeoff between increases in grain mass (as a result of selection) with reductions in grain numbers has been commonly reported in other crops, e.g., wheat, Triticum aestivum L. (Busch and Kofoid, 1982), although there are exceptions (Knott and Talukdar, 1971). In this experiment, selection for grain mass apparently exploited existing variation in ICMS 7703 in the grain numbergrain size relationship within individual panicles, without affecting the total sink size of the crop, and hence did not increase grain yield per square meter. The mild selection pressure for grain yield per square meter applied in both selection generations was evidently sufficient to prevent any loss in grain yield potential as a result of selection for grain mass, but not sufficient to increase both grain mass and grain yield per square meter simultaneously, even assuming that there was genetic variation for a simultaneous increase in both yield components. 


\section{Syn 0 vs. Syn 1 Evaluation of Progress}

The increase in individual grain mass resulting from the first cycle of selection appeared to be greater when the estimate was based on the Syn 0 recombination generation ( $16.3 \%$ in the 1985 and 1986 evaluations) than when it was based on the Syn 1 recombination generation (7.0\% in the 1989 to 1991 evaluations) (Table 2). The most likely explanation is that the 1985 and 1986 result is an overestimate, since it is based on only two field trials. However, an effect of recombination generation cannot be ruled out. Where there are substantial genetic differences among the lines being recombined (as in the case of parents of synthetic varieties) the expression of a trait would be expected to be greater in the first recombination generation than in later generations because of heterosis among diverse parental lines (Burton and Powell, 1968). We would have expected this effect of recombination generation to be small in the case of progenies extracted from the same open-pollinated variety, however. Whichever of the above explanations is correct, the $7 \%$ gain in grain mass per cycle measured in the Syn 1 generation in 1989 to 1991 is likely to be a more realistic estimate of progress than the $16 \%$ gain recorded in the Syn 0 generation in 1985 and 1985.

\section{Applications in Variety Breeding}

The results of this experiment suggest that it is possible to make reasonable progress in increasing individual grain mass by a modified phenotypic/S1 progeny selection, at least for several generations, without affecting grain yield. It would also be relatively easy to incorporate selection for increased grain mass into selection programs employing S1 progeny selection for qualitative characteristics such as bristles or seed color, or for highly heritable quantitative traits such as height, time to flowering, or disease resistance, provided that there were no negative genetic associations between grain mass and other traits under selection. For example, the selection procedure employed by Weltzien R. and King (1995) for improvement of downy mildew resistance could easily incorporate additional selection for seed size. Because larger seed size is a widely desired attribute, adding selection for increased individual grain mass should serve to increase the attractiveness of the resulting cultivars.

\section{ACKNOWLEDGMENTS}

The authors acknowledge the contribution of Dr. G. Alagarswamy who initiated the first cycle of selection in this experiment.

\section{REFERENCES}

Burton, G.W., and J.B. Powell. 1968. Pearl millet breeding and cytogenetics. Adv. Agron 20:49-89.

Busch, R.H., and K. Kofoid. 1982. Recurrent selection for kernel weight in spring wheat. Crop Sci. 22:568-572.

Chhina, B.S., and P.S. Phul. 1982. Association of seed size and seedling vigour with various morphological traits in pearl millet. Seed Sci. Tech. 10:541-545.

DeWet, J.M.J., F.R. Bidinger, and J.M. Peacock. 1992. Pearl Millet (Pennisetum glaucum) a cereal of the Sahel. p. 259-267. In G.P. Chapman (ed.) Desertified grasslands: Their biology and management. Academic Press, London.

Hash, C.T. 1986. Breeding for large grain size in pearl millet Pennisetum americanum (L.) Leeke. Ph.D. diss. Cornell Univ., Ithaca, NY.

Jain, R.P., S.B. Chavan, B.S. Talukdar, and D.J. Andrews. 1991. Registration of "ICMS 7703" pearl millet. Crop Sci. 31:1381-1382.

Khadr, F.H., and A.K. Oyinloye. 1978. Mass selection for grain yield and seed size in pearl millet "Pennisetum typhoides." Alexandria J. Agric. Res. 26:79-84.

Knott, D.R., and B. Talukdar. 1971. Increasing seed weight in wheat and its effect on yield, yield components and quality. Crop Sci. 11:280-283.

Lawan, M., F.L. Barnett, B. Kaleeq, and R.L. Vanderlip. 1985. Seed density and seed size of pearl millet as related to field emergence and several seed and seedling traits. Agron. J. 77:567-571.

Murthy, B.R., M.K. Upadhyay, and P.I. Manchanda. 1967. Classification and cataloguing of a world collection of genetic stocks of Pennisetum. In Catalogue of the world collection of sorghum and Pennisetum. Indian J. Genet. Plant Breed. 27:313-394 (special edition).

Phul, P.S., and D.S. Athwal. 1969. Inheritance in grain size and grain hardness in pearl millet. Indian J. Genet. Plant Breed. 29:184-191.

Rooney, L.W., and C.M. McDonough. 1987. Food quality and consumer acceptance of pearl millet. p. 43-61. In Proceedings of the International Pearl Millet Workshop, ICRISAT Center, India. 7-11 April 1986. ICRISAT, Patancheru, A.P. 502 324, India.

SAS. 1985. SAS users guide: Statistics users guide: Statistics Version 5th Edition. SAS Institute, Cary, NC.

Siband, P., I. Dieye, and B.C. Faye. 1978. Evolution ponderale du systeme grain-plantule chez le mil (Pennisetum typhoides) au cour de l'epuisement du grain. Agron. Trop. 34:250-257.

Virk, D.S. 1988. Biometrical analysis in pearl millet-a review. Crop Imp. 15:1-29.

Weltzien R., E., and S.B. King. 1995. Recurrent selection for downy mildew resistance in pearl millet. Plant Breed. 114:308-312. 